\title{
Comparison of closed-cell and hybrid-cell stent designs in carotid artery stenting: clinical and procedural outcomes
}

\author{
Ersan Tatli ${ }^{1}$, Alptug Tokatli ${ }^{2}$, Mehmet Bulent Vatan ${ }^{1}$, Mustafa Tarik Agac ${ }^{1}$, Huseyin Gunduz ${ }^{1}$, Ramazan Akdemir ${ }^{1}$, \\ Harun Kilic ${ }^{1}$
}

${ }^{1}$ Department of Cardiology, School of Medicine, Sakarya University, Sakarya, Turkey

2Department of Cardiology, Golcuk Military Hospital, Kocaeli, Turkey

Adv Interv Cardiol 2017; 13, 2 (48): 135-141

DOI: https://doi.org/10.5114/pwki.2017.67994

\begin{abstract}
A bstract
Introduction: Carotid artery stenting (CAS) is a promising alternative to surgery in high-risk patients. However, the impact of stent cell design on outcomes in CAS is a matter of continued debate.

Aim: To compare the periprocedural and clinical outcomes of different stent designs for CAS with distal protection devices.

Material and methods: All CAS procedures with both closed- and hybrid-cell stents performed at our institution between February 2010 and December 2015 were analyzed retrospectively. Adverse events were defined as death, major stroke, minor stroke, transient ischemic attack and myocardial infarction. Periprocedural and 30-day adverse events and internal carotid artery (ICA) vasospasm rates were compared between the closed-cell and hybrid-cell stent groups.

Results: The study included 234 patients comprising 146 patients with a closed-cell stent (Xact stent, Abbott Vascular) (mean age: $68.5 \pm 8.6 ; 67.1 \%$ male) and 88 patients with a hybrid-cell stent (Cristallo Ideale, Medtronic) (mean age: 67.2 $\pm 12.8 ; 68.2 \%$ male). There was no significant difference between the groups with respect to periprocedural or 30-day adverse event rates. While there was no difference in terms of tortuosity index between the groups, there was a higher procedural ICA vasospasm rate in the closed-cell stent group (35 patients, 23\%) compared with the hybrid-cell stent group (10 patients, 11\%) $(p=0.017)$.

Conclusions: The results of this study showed no significant difference in the clinical adverse event rates after CAS between the closedcell stent group and the hybrid-cell stent group. However, procedural ICA vasospasm was more common in the closed-cell stent group.
\end{abstract}

Key words: carotid artery stenosis, carotid artery stenting, stent design, closed cell, hybrid cell, outcomes.

\section{Introduction}

Stroke is one of the leading causes of death and a major cause of functional disability for adults [1]. Nearly $15 \%$ of all ischemic strokes originate from a stenosis in the internal carotid artery [2]. Traditionally, carotid endarterectomy has been considered the gold standard for the management of high-grade carotid artery stenosis. However, carotid artery stenting (CAS) is a promising alternative for surgery in patients at high risk of carotid artery stenosis.

Historically, the first stent design for CAS was a balloon-expandable closed-cell stent. Closed-cell stents are characterized by interconnected stent struts with small free cell areas, whereas the open-cell design has larger gaps between the struts. The hybrid-cell design stents consist of proximal and distal segments with an opencell design in combination with a central closed-cell seg- ment [3]. The effects of stent design on procedural and clinical outcomes after CAS remain to be established. Moreover, no efficacy or safety comparisons in terms of major adverse events and procedural outcomes between closed-and hybrid-cell stents for carotid artery stenosis have thus far been reported.

\section{Aim}

The aim of the present study was to compare the effect of closed-cell and hybrid-cell stent designs on periprocedural and clinical outcomes in patients with carotid artery stenosis who underwent CAS.

\section{Material and methods}

From February 2010 to December 2015, 234 patients who underwent CAS with closed or hybrid-cell stents were enrolled in this retrospective, single-centre

\section{Corresponding author:}

Alptug Tokatli MD, Department of Cardiology, Golcuk Military Hospital, 41910 Kocaeli, Turkey, phone: +90 5360177640 ,

e-mail: alptugtokatli@gmail.com

Received: 12.08.2016, accepted: 11.01.2017. 
study. Patients with ischemic stroke within the previous 30 days, total occlusion of the target vessel or contraindications for anti-platelet and/or anti-coagulant therapy were excluded. Anatomical criteria for exclusion were ostium of common carotid artery that requires surgery, target lesion that cannot be covered by one stent, ipsilateral intracranial stenosis requiring revascularization and intracranial arteriovenous malformation or aneurysm that requires treatment.

Indications for CAS included moderate ( $\geq 50 \%)$ symptomatic internal carotid artery (ICA) stenosis or severe ( $\geq 80 \%$ ) asymptomatic ICA stenosis determined by angiography. The percentage of ICA stenosis was calculated by angiography according to the North American Symptomatic Carotid Endarterectomy Trial (NASCET) criteria [4]. A multidisciplinary panel composed of a cardiologist, a cardiovascular surgeon and a neurologist evaluated the treatment options for patients. The patients were also integrated into a shared decision-making process for determining the optimal appropriate treatment option.

Demographic variables, clinical features, and operative and follow-up data were retrospectively analyzed from the database by the investigators. The study was approved by our Institutional Ethics Committee and written informed consent was obtained from all patients.

\section{Carotid artery stenting procedure}

All patients received oral acetylsalicylic acid $100 \mathrm{mg}$ and clopidogrel $75 \mathrm{mg}$ per day for 5 days before the procedure. All procedures were performed under local anesthesia. The femoral artery was punctured and after the sheath was placed into the artery, a bolus injection of heparin (80 IU/ $/ \mathrm{kg}$ ) was delivered to achieve an activated clotting time of 250-300 s.

The target carotid artery was selectively engaged with an appropriately shaped 6-French guiding catheter. The lesion was crossed with a 0.014-inch guidewire. A cerebral protection device was deployed to the ICA distal to the culprit lesion for all patients (Emboshield, Abbott Vascular, Redwood City, CA, USA). Predilatation was optional for the operator according to the lesion characteristics, and, if necessary, low profile balloons were used for this purpose. Atropine (0.5-1 mg) was administered intravenously if the patient developed hypotension and bradycardia during the procedure.

Carotid artery stenting was applied using self-expandable stents. Although the beneficial effects have not been proven in prospective studies, some retrospective analysis suggest that the use of closed-cell stents may be associated with lower adverse events rates after CAS compared with open-cell stents. So we designed the study to compare closed-cell and hybrid-cell stent design. Stent types used for CAS were determined according to the physician's choice and lesion characteristics; e.g. lesions with suspected high embolic potential were primarily treated with closed-cell stents, and hybrid-cell configuration was preferred in angulated or tortuous vessels. The stent size was based on the estimated diameter of the carotid artery. In the closed-cell stent group, XACT stents (Abbott Vascular, Illinois, USA) were used. In the hybrid-cell stent group the deployed stents were Cristallo Ideale stents (Medtronic, Invatec, Roncadella, Italy). All stents were made of nitinol. Post-dilatation was also performed if residual stenosis after stent placement was $>30 \%$. Angiographic controls were performed after the procedure to evaluate stent clearance (Figures 1, 2).

\section{Definitions and follow-up}

All complications or death occurring during the procedure or within the follow-up were analyzed from the recorded database. Major adverse events were defined as death, stroke, myocardial infarction and transient ischemic attack (TIA).

Neurological evaluation was performed before, immediately after, at $24 \mathrm{~h}$ and at 30 days after the study procedure. Neurological examination was applied using the National Institutes of Health Stroke Scale (NIHSS) [5]. Sustained neurological dysfunction for over 24 hours with an NIHSS score $>4$ was defined as major stroke. Focal neurological deficit lasting more than $24 \mathrm{~h}$ with an NIHSS score $<4$ was defined as minor stroke. The TIA was defined as a new neurological deficit lasting less than $24 \mathrm{~h}$. Myocardial infarction was diagnosed by an increase in cardiac biomarkers (creatine kinase-MB or cardiac troponins) three times the upper reference limit with electrocardiographic changes or symptoms consistent with myocardial ischemia. Hyperperfusion syndrome was defined as ipsilateral migraine-like headache, seizure and transient focal neurological deficit in the absence of cerebral ischemia and demonstration of hyperperfusion on perfusion magnetic resonance imaging or computed tomography scan. As a procedural event, significant carotid artery vasospasm was defined as a stenosis of $70 \%$ or more than the carotid arterial luminal diameter. The carotid artery diameters were measured by quantitative carotid angiography (QCA) before and after the procedure at the site that showed the greatest changes. Reference vessel diameters were measured at the proximal and distal portions of the artery. The mean reference vessel diameter was used to assess diameter narrowing by QCA. The tortuosity index ( $\mathrm{TI})$ was defined as the sum of all angles diverging from the ideal straight axis; the ideal origin of the innominate or the left common carotid artery from the arch was considered as a $90^{\circ}$ angle from the axis of the carotid and the tangent of the arch, irrespective of the arch type [6]. Technical success was defined as successful stent deployment with residual stenosis $<30 \%$.

After the procedure all patients received acetylsalicylic acid $100 \mathrm{mg}$ and clopidogrel $75 \mathrm{mg} /$ day for 4 weeks. 

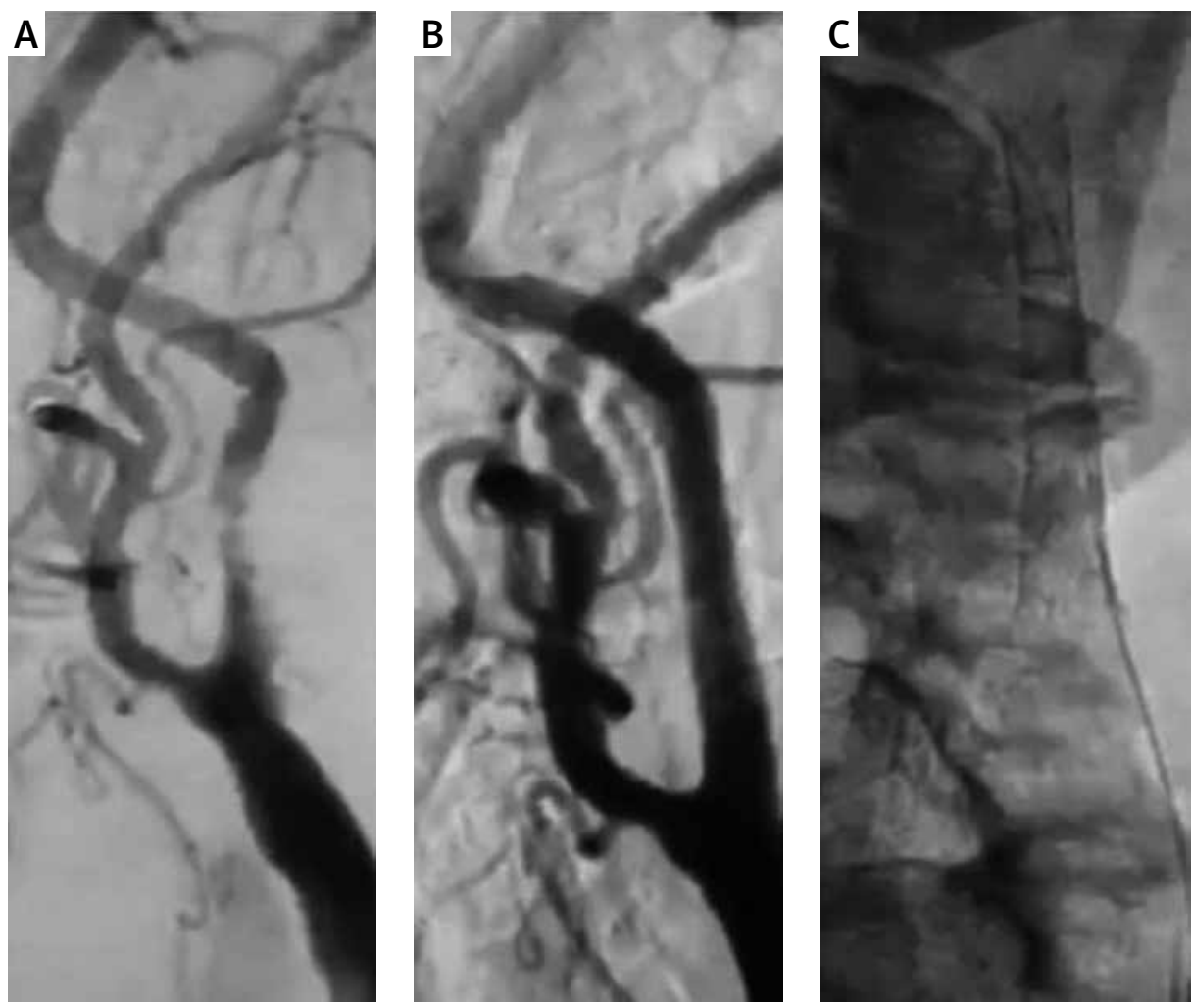

Figure 1. Carotid artery stenting with a closed-cell stent: A - significant stenosis of the internal carotid artery was established by selective angiography, $\mathbf{B}$ - final angiographic result after stent deployment, $\mathbf{C}$ - fluoroscopic image of the closed-cell stent shows very low flexibility
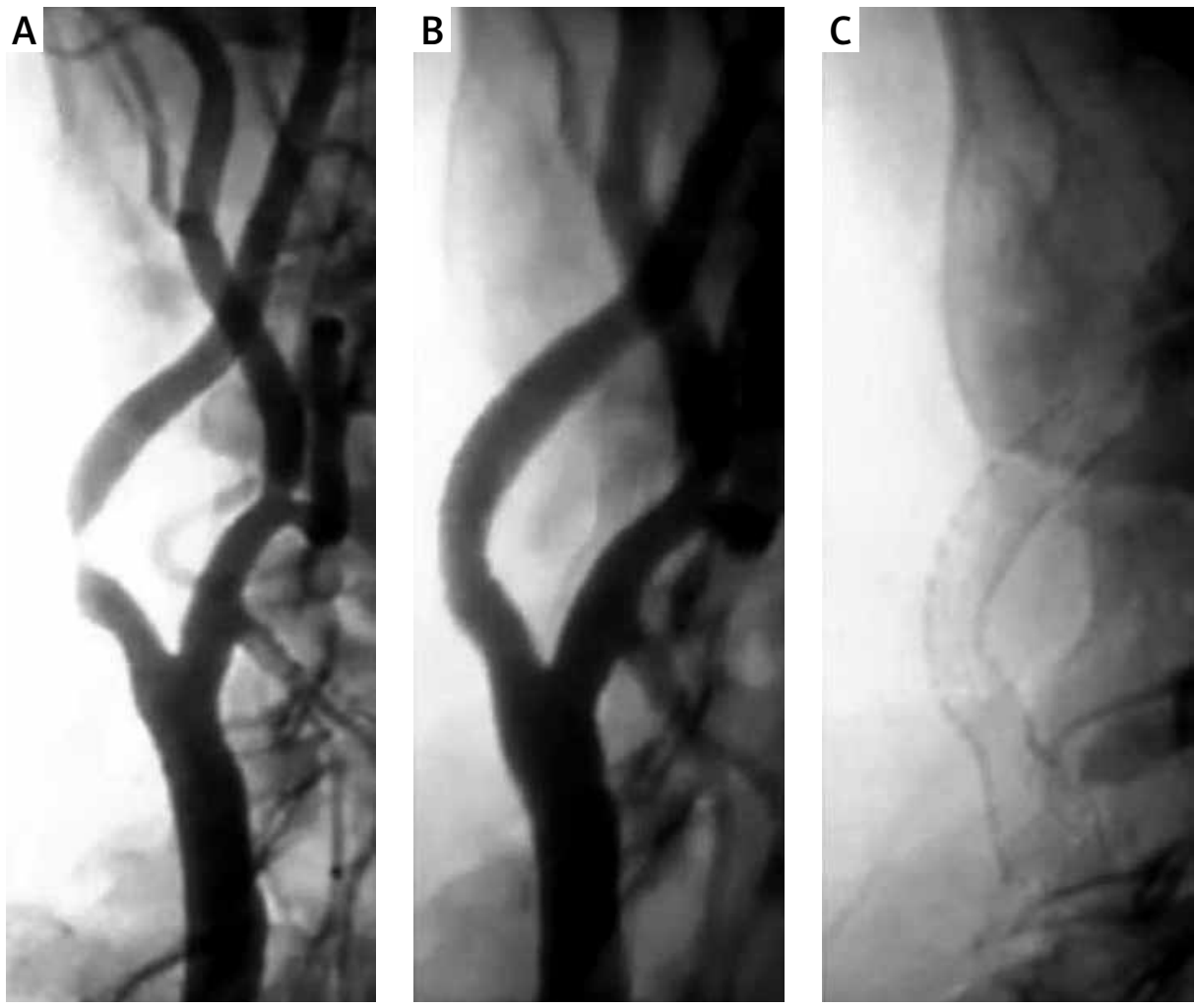

Figure 2. Carotid artery stenting with a hybrid-cell stent: $\mathbf{A}$ - significant stenosis of the internal carotid artery was established by selective angiography, B - final angiographic result after stent deployment, $\mathbf{C}$ - fluoroscopic image of the hybrid-cell stent shows high flexibility 
The continuation of one of the above-mentioned antiplatelet therapies as a lifelong therapy was recommended for all patients.

\section{Statistical analysis}

All statistical analysis was performed using SPSS statistical software (SPSS, Chicago, IL). Values of continuous variables were stated as mean \pm standard deviation or the data were reported as the number $(n)$ and percentage (\%). In the comparison of categorical and continuous variables, the $\chi^{2}$ test and Student's t test were used, respectively. A value of $p<0.05$ was considered statistically significant.

\section{Results}

A single-center retrospective analysis was made of the data of 234 patients (158 males/76 females; mean age: $67 \pm 11$ years) with carotid artery stenosis who were hospitalized with a diagnosis of CAS between February 2010 and December 2015 at our institution. Of the total study population, 146 patients received closed-cell stents and 88 patients received hybrid-cell design stents.

Overall, 209 (89.3\%) patients had symptomatic and $25(10.7 \%)$ patients had asymptomatic carotid stenosis. The most common indications for CAS in symptomatic subjects were stroke in 117 (56\%) patients, TIA in 71 (34\%) patients and amaurosis fugax in 21 (10\%) patients.

There was no significant difference between the groups in terms of age, gender, body mass index, hypertension, diabetes mellitus or basic laboratory findings, but there was a statistically significant difference with respect to coronary artery disease and smoking status (Table I). As shown in the table, the stenosis grade and mean duration of the procedure were also similar between the groups. The procedural success rate was $100 \%$ for all patients. Emboli protection devices were used in all performed procedures. Predilatation before stenting was achieved in $42(28.8 \%)$ patients in the closed-cell stent group and in 17 (19.3\%) patients in the hybrid-cell stent group $(p=0.260)$.

Between the closed-cell stent group and the hybrid-cell stent group lesion length was comparable (17.0 \pm 6.2 vs. $16.6 \pm 7.0 ; p=0.46$, respectively). There was no difference between the groups with respect to the tortuosity index (100.1 \pm 62.1 vs. $104.9 \pm 59.7 ; p=0.37$, respectively), but there was a greater incidence of ICA vasospasm in the closed-cell stent group compared to the hybrid-cell group (35 vs. 10; $p=0.017$, respectively). No significant difference was found in the rates of post-dilatation procedure between the closed-cell and hybrid-cell stent groups (69.2\% vs. $81.8 \% ; p=0.32$, respectively) (Ta-

Table I. Demographic and clinical characteristics of patients

\begin{tabular}{|c|c|c|c|}
\hline Variables & $\begin{array}{l}\text { Closed-cell group } \\
(n=146)\end{array}$ & $\begin{array}{l}\text { Hybrid-cell group } \\
\qquad(n=88)\end{array}$ & $P$-value \\
\hline Age [years] & $68.5 \pm 8.6$ & $67.2 \pm 12.8$ & 0.65 \\
\hline Male, $n(\%)$ & $98(67.1)$ & $60(68.2)$ & 0.12 \\
\hline Body mass index $\left[\mathrm{kg} / \mathrm{m}^{2}\right]$ & $28.1 \pm 7.6$ & $27.6 \pm 8.7$ & 0.70 \\
\hline $\mathrm{SBP}[\mathrm{mm} \mathrm{Hg}]$ & $134.8 \pm 26.7$ & $136.4 \pm 27.1$ & 0.32 \\
\hline Symptomatic carotid stenosis, $n(\%)$ & $123(84.2)$ & $60(68.2)$ & 0.17 \\
\hline \multicolumn{4}{|l|}{ Risk factors, $n(\%)$ : } \\
\hline Hypertension & $125(85.6)$ & $60(68.2)$ & 0.10 \\
\hline Diabetes mellitus & $62(42.5)$ & $34(38.6)$ & 0.56 \\
\hline Current smoker & $48(33)$ & $70(79.5)$ & 0.035 \\
\hline Coronary artery disease & $35(24)$ & $32(36.4)$ & 0.042 \\
\hline Peripheral artery disease & $8(5.5)$ & $5(5.6)$ & 0.20 \\
\hline \multicolumn{4}{|l|}{ Baseline laboratory parameters [mg/dl]: } \\
\hline Total cholesterol & $195.1 \pm 40.1$ & $187.7 \pm 46.4$ & 0.28 \\
\hline$\overline{\mathrm{LDL}}$ & $126.1 \pm 40.2$ & $120.7 \pm 36.8$ & 0.24 \\
\hline $\mathrm{HDL}$ & $41.4 \pm 12.1$ & $33.9 \pm 9.5$ & 0.36 \\
\hline Uric acid & $5.6 \pm 1.9$ & $5.3 \pm 2.4$ & 0.32 \\
\hline Creatinine & $1.1 \pm 0.4$ & $1.3 \pm 0.7$ & 0.22 \\
\hline
\end{tabular}

Values are means $\pm S D$. $L D L$-low-density lipoprotein, $H D L$ - high-density lipoprotein. 
ble II). There was also no significant difference between the groups with respect to the mean hospitalization duration ( $2.2 \pm 1.4$ vs. $2.6 \pm 1.2 ; p=0.625$, respectively) or NIHSS scores before and after the procedure. No acute adverse angiographic events such as malapposition, plaque protrusion, impaired stent integrity or migration were observed in either group.

Fifteen defined complications were identified in the study population. The total complication rate was $6.4 \%$. The average duration of follow-up for the whole group was $36 \pm 11$ months. There were no significant differences between the groups in terms of death, major stroke, minor stroke, TIA, MI or hyperperfusion syndrome (Table III). During the follow-up there was no re-stenosis in any patient. The only mortality due to an acute major stroke on the table in the angio room occurred in the closed-cell stent group. Three of the four major strokes in the closedcell stent group occurred during the procedure defined as intraprocedural stroke and the stented segment was patent. The other major stroke occurred after a symptom-free interval at the ward on day 0 . In this patient patency was assessed by angiography and the carotid artery was found patent and clear of thrombus. Outcome of all strokes was non-disabling. Three minor stroke events occurred after the procedure between day 1 and day 7 .
Minor strokes might have been caused by hemodynamic complications. There were no major access site complications that required intervention and blood transfusion and no prolonged episodes of bradycardia which required permanent transvenous pacing in any patient.

\section{Discussion}

In the present study, analysis was made of 234 CAS procedures performed over a 5 -year period and a retrospective investigation was made of the influence of different stent types on the procedural and clinical effects of CAS according to closed-and hybrid-cell stent designs. The results of the study showed no significant differences between the two groups of stent design with respect to the rates of death, major stroke, minor stroke, TIA and MI. While the tortuosity index was similar between the groups, there was a higher procedural ICA vasospasm rate in the closed-cell stent group compared to the hybrid-cell stent group.

Improvement in stent device technologies have increased the safety and efficacy in CAS. One of the important issues in device innovation is stent design. The treatment of carotid artery stenosis was first achieved by balloon expandable stents in the late 1980s. However, major concerns concentrated on stent distortion with

Table II. Procedural data of the study groups

\begin{tabular}{lccc} 
Variables & $\begin{array}{c}\text { Closed-cell group } \\
(n=146)\end{array}$ & $\begin{array}{c}\text { Hybrid-cell group } \\
(\boldsymbol{n}=\mathbf{8 8})\end{array}$ & $16.6 \pm 7.0$ \\
\hline Lesion length $[\mathrm{mm}]$ & $17.0 \pm 6.2$ & $73 \pm 12$ & 0.46 \\
\hline Stenosis grade $(\%)$ & $78 \pm 14$ & $25 \pm 7$ & 0.20 \\
\hline Mean duration of procedure [min] & $28 \pm 9$ & $17(19.3)$ & 0.32 \\
\hline Pre-dilatation, $n(\%)$ & $42(28.8)$ & $72(81.8)$ & 0.26 \\
\hline Post-dilatation, $n(\%)$ & $101(69.2)$ & $10(11.4)$ & 0.32 \\
\hline ICA vasospasm, $n(\%)$ & $35(23)$ & $104.9 \pm 59.7$ & 0.017 \\
\hline Tortuosity index & $100.1 \pm 62.1$ & $34(38.6)$ & 0.37
\end{tabular}

Values are means $\pm S D$. ICA - internal carotid artery, RICA - right internal carotid artery.

Table III. Clinical outcomes according to the groups

\begin{tabular}{lccc} 
Variables & $\begin{array}{c}\text { Closed-cell group } \\
(\boldsymbol{n}=146)\end{array}$ & $\begin{array}{c}\text { Hybrid-cell group } \\
(\boldsymbol{n}=\mathbf{8 8})\end{array}$ & $0(0)$ \\
\hline Major stroke & $4(2.7)$ & $2(2.3)$ & 0.12 \\
\hline Minor stroke & $1(0.7)$ & $1(1.1)$ & 0.29 \\
\hline Hyperperfusion syndrome & $2(1.3)$ & $1(1.1)$ & 0.87 \\
\hline TIA & $3(2)$ & 0.59 & $0(0)$
\end{tabular}

Values are means $\pm S D$. TIA-transient ischemic attack. 
balloon expandable stents. This problem has been overcome with the advent of self-expandable stents. Depending on the stent configuration, stents can be classified as those with a closed-cell or open-cell design. The hybrid-cell stent design is characterized by a closed-cell design in the mid part and an open-cell design in the proximal and distal parts. The closed-cell stents have superior scaffolding and resistance, although these benefits have a cost in flexibility. In contrast, the flexion benefits of the open-cell design interfere with scaffolding uniformity [7]. As the open-cell frame allows a high degree of flexibility and conformity to the vessel anatomy and the closed-cell portion provides a high degree of plaque scaffolding that can reduce plaque prolapse with hybrid-cell stents, these stents incorporate the advantages of open- and closedcell stent technology. This is true in theory, but there has not been enough evidence to support it so far.

The impact of stent design on clinical and procedural outcomes in CAS has not been adequately addressed. Furthermore, to date there has been no prospective study that has investigated the difference between stent designs. Although proper implantation of hybrid-cell stents results in coverage of the plaque with the closed-cell section of the stent, the distal open-cell part will allow better flexibility. So it may be reasonable to expect an outcome difference between hybrid-cell and closed-cell stents. In a study focusing on the interaction between carotid plaques and stents by analysis with optical coherence tomography (OCT), the findings according to stent design showed higher rates of malapposed struts in closed-cell stents compared to open-cell and hybrid-cell stents. On OCT analysis, plaque prolapse was more common with open-cell than closed-cell designs [8]. Alparslan et al. [9] evaluated 155 patients who underwent the CAS procedure with openand closed-cell stents and found no significant difference in terms of periprocedural complications between the groups. It was concluded that even though in-stent re-stenosis was more common in the open-cell design group, no difference was detected in clinical outcomes. A review by Liu et al. [10] also revealed no significant differences in the rates of neurological complications, cardiovascular events or stent re-stenosis rates between open- and closed-cell stents. In another non-randomized retrospective study, no difference was observed in clinical outcomes or stent patency at follow-up between open- and closed-cell stents [11]. While some data suggest no difference in different stent types with respect to clinical outcomes, there have also been conflicting results from previous studies. According to a retrospective study by Hart et al. [12], a significantly lower rate of stroke, TIA and death was observed with closed-cell stents compared to open-cell design. This result may be attributable to greater plaque coverage with closed-cell design stents, which in turn prevents plaque embolization. Another observational study also showed that the use of closed-cell stents is associated with lower stroke and death rates compared to open-cell stents [3].
Park et al. [13] evaluated the influence of stent design on the influence of procedural and post-procedural embolism associated with CAS, and they observed significantly more frequent new lesions on post-procedural diffusion-weighted imaging in the open-cell than in the closed-cell stent group. In the current study, death, stroke, $\mathrm{MI}$ and TIA rates after the procedure were no different between the closedcell and hybrid-cell stent groups. Therefore, these results do not favor a specific stent cell design with respect to major adverse events.

Distal vasospasm and slow flow associated with CAS have been described with an incidence of 3.6-7.2\% [14]. Distal vasospasm may even be related to distal protection devices or stents. In a previous study conducted by our group, periprocedural ICA vasospasm was found to be significantly higher in the distal filter protection group compared to proximal protection during CAS [15]. In the present study, the distal ICA vasospasm rate was significantly higher in the closed-cell stent group in comparison to the hybrid-cell stent group. The basic mechanism of vasospasm induced by stents may be partially explained by radial force. The free cell area is small and vessel wall support is better with closed-cell stents, causing endothelial irritation throughout the full stent length compared to hybrid-cell stents with an open-cell segment in the proximal and distal part of the stent with low radial force. A high tortuosity index, long procedural duration and female gender are independent risk factors for vasospasm during CAS [16]. However, in the current study, there was no difference in these factors between the groups. Although it is not possible to state with certainty whether these findings about ICA vasospasm are of any clinical or prognostic importance, vasospasm is usually self-limiting and easy to treat. Hemodynamic consequences were evaluated in patients with CAS and carotid endarterectomy. Huibers et al. demonstrated that hemodynamic disturbance is an important mechanism for complications after carotid interventions [17].

There are some limitations to this study. The study was a single-center, retrospective study with the known limitations of such studies. The study considered closedcell and hybrid-cell stent design but not open-cell stent design. To be able to generalize the results, all kinds of devices should be tested. Stent type choice was at the discretion of the physician, which was therefore a source of possible selection bias.

\section{Conclusions}

The present study showed no difference between the clinical periprocedural and 30-day adverse event rates of closed-cell stents and hybrid-cell stents in CAS. However, the closed-cell stent design showed higher rates of periprocedural ICA vasospasm. Further prospective, multicenter trials are needed to elucidate the effect of stent design in CAS on procedural and clinical outcomes. 


\section{Conflict of interest}

The authors declare no conflict of interest.

\section{References}

1. Mozaffarian D, Benjamin EJ, Go AS, et al. Heart disease and stroke statistics: 2016 update: a report from the American Heart Association. Circulation 2016; 133: 447-54.

2. Cremonesi A, Castriota F, Secco GG, et al. Carotid artery stenting: an update. Eur Heart J 2015; 36: 13-21.

3. Bosiers M, Donato G, Deloose K, et al. Does free cell area influence the outcome in carotid artery stenting? Eur J Vasc Endovasc Surg 2007; 33: 135-41.

4. Ferguson GG, Eliasziw M, Barr HW, et al. The North American Symptomatic Carotid Endarterectomy Trial: surgical results in 1415 patients. Stroke 1999; 30: 1751-8.

5. Brott T, Adams HP Jr, Olinger CP, et al. Measurements of acute cerebral infarction: a clinical examination scale. Stroke 1989; 20: 864-70.

6. Faggioli G, Ferri M, Gargiulo M, et al. Measurement and impact of proximal and distal tortuosity in carotid stenting procedures. J Vasc Surg 2007; 46: 1119-24.

7. Müller-Hülsbeck S, Schäfer PJ, Charalambous N, et al. Comparison of carotid stents: an in-vitro experiment focusing on stent design. J Endovasc Ther 2009; 16: 168-77.

8. De Donato G, Setacci F, Sirignano P, et al. Optical coherence tomography after carotid stenting: rate of stent malapposition, plaque prolapse and fibrous cap rupture according to stent design. Eur J Vasc Endovasc Surg 2013; 45: 579-87.

9. Alparslan B, Nas OF, Eritmen UT, et al. The effect of stent cell geometry on carotid stenting outcomes. Cardiovasc Interv Radiol 2016; 39: 507-13.

10. Liu YM, Qin H, Zhang B, et al. Efficacy of different types of self-expandable stents in carotid artery stenting for carotid bifurcation stenosis. J Huazhong Univ Sci Technolog Med Sci 2016; 36: 95-8.

11. Maleux G, Marrannes J, Heye S, et al. Outcome of carotid artery stenting at 2 years follow-up: comparison of nitinol open cell versus stainless steel closed cell stent design. J Cardiovasc Surg (Torino) 2009; 50: 669-75.

12. Hart JP, Peeters P, Verbist J, et al. Do device characteristics impact outcome in carotid artery stenting? J Vasc Surg 2006; 44: 725-30.

13. Park KY, Kim DI, Kim BM, et al. Incidence of embolism associated with carotid artery stenting: open-cell versus closed-cell stents. J Neurosurg 2013; 119: 642-7.

14. Reimers B, Corvaja N, Moshiri S, et al. Cerebral protection with filter devices during carotid artery stenting. Circulation 2001; 104: $12-5$.

15. Tatli E, Buturak A, Grunduz Y, et al. Comparison of anti-embolic protection with proximal balloon occlusion and filter devices during carotid artery stenting: clinical and procedural outcomes. Postep Kardiol Interw 2013; 9: 221-7.

16. Wang Q, Liu C, Yan B, et al. Correlation of extracranial internal carotid artery tortuosity index and intraprocedural complications during carotid artery stenting. Eur Neurol 2012; 68: 65-72.

17. Huibers A, Calvet D, Kennedy F, et al. Mechanism of procedural stroke following carotid endarterectomy or carotid artery stenting within the International Carotid Stenting Study (ICSS) randomised trial. Eur J Vasc Endovasc Surg 2015; 5: 281-8. 